\title{
Mentoring senior house officers. Is there a role for middle grade doctors?
}

\author{
C D Okereke, M Naim
}

\begin{abstract}
Objectives-To determine whether the mentoring scheme currently used has an impact on the training of senior house officers and also determine if they are willing to accept middle grade mentors.

Methods-A questionnaire comprising 10 questions was sent to all the senior house officers employed in the emergency departments of two large inner city teaching hospitals and three large district hospitals. Most of the questions required a simple yes/no response.

Results-Most of the senior house officers had mentors allocated to them but felt the scheme was not satisfactory probably because they had low expectations. Most were happy to have middle grade doctors as mentors.
\end{abstract}

Conclusions-Senior house officers have a low expectation of the present system and seem willing to accept middle grade doctors as mentors.

(Emerg Med f 2001;18:259-262)

Keywords: mentoring

According to Homer's odyssey, in ancient Greece Odysseus entrusted the education of his son Telemachus to a friend. This trusted and good friend "Mentor" became the counsellor, guide, tutor, coach and sponsor for this his protégé, Telemachus. ${ }^{1}$ Mentoring relationships are thought to be important to career development in many professional fields such as business, education and law. Medicine is no different. ${ }^{2}$ Certainly in nursing, mentoring as a concept and its practice has been widely accepted as an important aspect of clinical supervision. ${ }^{3}$ Few objective data are available about the effects of mentoring on the development of medical careers. However, what research is available and overwhelming anecdotal evidence indicates the importance of mentoring. ${ }^{1}$ The mentor-mentee relationship is beneficial to all involved. ${ }^{4}$

Over the years working as middle grade doctors in accident and emergency (A\&E) departments, we have seen many senior house officers go through the departments feeling unsupported. The introduction of mentoring for senior house officers in the A\&E departments was meant to tackle these issues. Anecdotally, little seems to have changed. This sense of disillusionment is evident when we engage the senior house officers in discussions and is more apparent among ethnic minorities and female doctors.

With these personal observations in mind, we carried out a survey of the senior house officers in the A\&E departments of the two large teaching hospitals and three district general hospitals seeing more than 50000 patients a year.

The objectives of this study were:

(1) To determine if the senior house officers understood the concept of mentoring.

(2) To determine if the mentoring scheme was working.

(3) To determine if the scheme had any positive or negative impact on their training.

(4) To determine whether they felt the consultants currently mentoring them acted as effective mentors.

(5) To determine whether they were willing to accept middle grade doctors as mentors.

\section{Methods}

A questionnaire comprising 10 questions (appendix 1) was sent to all the A\&E senior house officers employed by two large inner city teaching hospitals and three large district hospitals. There were 44 doctors ( 15 female and 29 male) of whom 11 were from ethnic minorities. The mean age was 26 years. Fourteen of them were either general practice trainees or on a surgical rotation, the rest were on a six month stand alone job. All senior house officers employed for over five months were eligible to enter the survey. All were contacted by post or had the questionnaire handed to them in person. The completed questionnaires were returned by mail or put in a labelled box left in the departments. The questionnaires were anonymous.

\section{Results}

The three district hospitals surveyed did not have a recognised mentoring scheme and were therefore excluded from further analysis. Twenty three of the 25 questionnaires (92\%) from the teaching hospitals were completed and returned. All the responders said they were familiar with the concept of mentoring; however when asked to define mentoring, only 10 of the responders (43\%) gave a recognised definition of mentoring (table 1). Although they did not give a clear definition of mentoring, their answers suggested they had an idea of what mentoring involved. All of the responders had a designated mentor of whom $22(96 \%)$ had a mentor assigned to them. Only $17(74 \%)$ had met with their mentors while six $(26 \%)$ had never met with their mentors. Of the number that had met their mentors, 12 $(71 \%)$ had only met with their mentors once.

Fourteen $(61 \%)$ of the responders felt that mentoring had not helped them approach the difficulties of working in an A\&E department while nine $(39 \%)$ felt that the mentoring was 
Table 1 Results of the questionnaire

\begin{tabular}{lll}
\hline & Yes (\%) & No (\%) \\
\hline Familiar with the concept of mentoring? & $23(100)$ & 0 \\
Designated mentor? & $23(100)$ & 0 \\
Assigned mentor? & $22(96)$ & $1(4)$ \\
Meet with mentor? & $17(74)$ & $6(26)$ \\
Help with difficulties in department? & $9(39)$ & $14(61)$ \\
Meet with expectations? & $13(57)$ & $10(43)$ \\
Consultants give time and commitment? & $8(35)$ & $15(65)$ \\
Limit mentors to consultants? & $4(17)$ & $19(83)$ \\
Accept middle grade as mentor? & $21(91)$ & $2(9)$ \\
\hline
\end{tabular}

helpful during the difficult times in the department. The majority felt there had been no feedback on their performances from their mentors.

When asked if mentoring had met with their expectations, $13(57 \%)$ said yes while 10 $(43 \%)$ said no. The positive responders however stated that they had a rather low expectation of mentoring.

Nineteen $(83 \%)$ of the responders felt that mentoring should not be limited to consultants while four $(17 \%)$ felt it should be. These responders felt that consultants were the best people to help with their careers. Those who felt that it should not be limited to consultants gave various reasons such as, "We have greater contact with the middle grades and the middle grades appear more current in career planning”.

On the question of whether they thought consultants had the time and commitment to act effectively as mentors, $15(65 \%)$ said "no" while eight $(35 \%)$ said "yes". The positive responders stated that they often had to actively seek out the consultants.

When asked if they were prepared to accept middle grade doctors as mentors 21 (91\%) said "yes" while two (9\%) said "no". The positive responders felt that their relationship with the middle grade was very good and that acting as mentors would be a natural progression. They also felt that the middle grade doctors were more readily available and would have more time and show more commitment. The responders that replied "no" felt they would be uncomfortable discussing private issues with middle grade doctors.

\section{Discussion}

WHY MENTOR?

The SCOPME ${ }^{5}$ report of 1998 defined mentoring as "a process whereby an experienced, highly regarded person (the mentor) guides another individual (the mentee) in the development and examination of their own ideas, learning and personal and professional development". The report also states that the process should not relate to nor form part of an organisational system of assessments or appraisals.

One may ask whether mentoring is effective. In the classic study by Roche $75 \%$ of the top 1250 executives in the United States stated that they had been mentored. They earned $28 \%$ more money, were more likely to have advanced degrees, were happier with their work and, more importantly, were more likely to mentor others. Johnson et al quote the work of Blackwell who in one of the few studies of mentoring of African American graduates and professional students found a significant, positive relation between having a mentor during a degree programme and later occupational status. Levinson et $a l^{8}$ found that women faculty members with mentors published more, spent more time on research activities and were more satisfied with their careers. A study of general practitioners (GPs) showed that mentors can make a significant contribution to the professional development of GPs and can increase their sense of well being. ${ }^{4}$

Mentoring often occurs informally, sometimes without a clear beginning or end, when two people with common interests simply find each other. ${ }^{9}$ Unfortunately, access to informal mentors may be barred for some, including women and minorities, hence the need for a formal mentoring structure. Morzinski et $a l^{10}$ reviewed the mentoring literature and identified five overlapping stages to guide development of a formal mentoring programme for academic physicians: (1) organisational readiness, (2) participant recruitment, (3) mentormentee matching and orientation, (4) ongoing mentor-mentee activities and (5) evaluation.

\section{PRESENT SYSTEM}

The current system as practised in the hospitals surveyed is a formal mentoring structure that entails the allocation of a mentor to each senior house officer when they start work. The 25 prospective mentees had eight mentors available to them. This mentor often served as the appraiser.

The senior house officer is told to contact his mentor if he has any problems. The structure does not specify the mode, frequency or location of contact. Details of the relationship are not outlined nor are priorities detailed. As the senior house officer is not allowed to chose his mentor the present system seems to give the impression that once a mentee has an assigned mentor, that mentor is sufficient.

Informal discussions with the mentors suggest that some have not had any training or preparations for the role of a mentor. Even with preparations for the role, Wright ${ }^{11}$ observed that some mentors experience difficulties with time availability because of staff shortages, management functions, increased work load and unpredictable events. Another problem identified is shift work. Often when the consultants are available to see the SHO, they are off duty or on night shift. This may explain our survey findings that only $74 \%$ had ever met with their mentors of which $71 \%$ had met their mentors once. Another explanation may be that $96 \%$ had mentors allocated to them.

\section{RECOMMENDATION}

Spouse $^{12}$ showed that nurses who have been qualified for a minimum of one year and undergone the ENB 998 course plus a short induction course made effective mentors. Raggins and Cotton $^{13}$ suggested that formal mentoring relationships may be quite useful for immediate performance measures such as on 
the job training or as an impetus for the development of early career and performance goals.

We have noted that the problems with the mentoring scheme in its current format is the time availability (only 35\% felt the consultants had the time and commitment) and a poor definition. We feel that an organisation, perhaps the postgraduate deanery, should identify pools of potential mentors (middle grades and consultants) and train these people in the skills necessary for effective mentoring. Training programmes should include strategies and skills for developing relationships with informal mentors. This pool will allow for a greater mix of people. It will further the mentoring structure and result in fewer numbers of mentees per mentor leading to increased time availability.

We suggest that this scheme should be in the form of a voluntary assignment of mentors and mentees by a programme coordinator on the basis of application forms by the potential mentor and mentee. ${ }^{14-16}$ The goals should be specified by the programme coordinator at the start of the relationship. The mode, frequency and location of contact should be specified by the mentor and mentee if possible. ${ }^{16}{ }^{17}$ The ongoing mentor-mentee activity would involve bimonthly meetings to discuss career plans and how they match the departments' expectations for faculty productivity. Details of the relationship such as purpose, goals and limitations should be discussed during this period. ${ }^{18}$ Group activities should be designed to facilitate interaction among all programme participants such as pub night outs, picnics and luncheons. These will allow discussions on the mentoring programmes and progress within an informal setting. Mentees with formal mentors should be encouraged to identify and select informal mentors. It is also important that mentees should have the opportunity to change mentors. All these will hopefully raise the profile of the scheme.

In reality, no one person has all the attributes of a "good" mentor and mentees would be better served by a mentoring team rather like a supervising team instituted by some higher education establishment for students undertaking postgraduate research. ${ }^{19}$

\section{LIMITATIONS OF THE STUDY}

The authors recognise this study has a number of limitations. The number of senior house officers taking part was very small. This is because the other hospitals surveyed did not have a mentoring system. The senior house officers may have been biased towards giving a favourable response knowing that middle grade doctors conducted the survey. Nevertheless, we feel that this possible acquiescence bias would not have affected the results of the survey. This is a small scale study, intended only to provoke discussion and should therefore not be generalised. We also recognise that the survey is a quantitative method of research with obvious limitations.
CONCLUSION AND SUGGESTIONS FOR THE FUTURE We feel that middle grade doctors especially in the A\&E department are in a unique position. They already, by virtue of the working conditions, find themselves in regular close contact with the senior house officers. They are thus able to offer practical advice, emotional support and feed back where necessary. Offering middle grade doctors the time and resources necessary to serve as mentors will also provide philosophical support and a sense of fulfilment. Finally, a qualitative method of research in this area involving interviews with mentees, observation of the mentoring process and focus groups could all be used to explore this issue further. A long term study looking at the effects of mentoring on young medical graduates through their training period would certainly be welcome.

Contributors

Chikezie Dean Okereke, guarantor of the article, initiated and coordinated the formulation of the core ideas, design of the survey, background research and writing of the report. Mukarram Naim was involved with collection and analysis of the survey, and background research.

Conflicts of interest: none.

Funding: none.

\section{Appendix 1}

1 Are you familiar with the concept of mentoring? Yes/ No.

2 Please explain what you understand by mentoring?

3 Do you have a designated mentor? Yes/No.

4 If yes, did you have a mentor allocated to you or did you choose your mentor?

5 Have you ever met with your mentor? If yes, how often do you meet with your mentor?

6 Do you feel the mentoring scheme has helped you with the difficulties in the department? Yes/No.

7 Do you feel the mentoring scheme has met with your expectations? Yes/No.

8 Do you feel that consultants as mentors have the time and commitment to address your problems? Yes/No.

9 Do you think the role of mentors should be limited to consultants only? Yes/No.

10 Are you prepared to accept a middle grade doctor as a mentor if he/she is trained? Yes/No.

1 Barr LL, Shaffer K, Valley K, et al. Mentoring: applications for the practice of radiology. Invest Radiol 1993;28:71-5.

2 Palepu A, Friedman RH, Barnett RC, et al. Junior faculty members' mentoring relationships and their professional development in U.S. medical schools. Acad Med 1998;73: 318-23.

3 Watson NA. Mentoring today: the students view. $\mathcal{F}$ Adv Nurs 1999;29:254-62.

4 Freeman R. Towards effective mentoring in general practice. Br 7 Gen Pract 1997;47:457-60.

5 The Standing Committee on Postgraduate Medical and Dental Education. An enquiry into mentoring. London: SCOPME, 1998.

6 Roche GR. Much ado about mentors. Harvard Business Review 1979;57:14-28.

7 Johnson JC, Williams B, Jayadevappa R. Mentoring program for minority faculty at the university of Pennsylvaprogram for minority faculty at the university of Pen
nia school of medicine. Acad Med 1999;74:376-9.

8 Levinson W, Kaufman K, Clark B, et al. Mentors and role Levinson W, Kaufman K, Clark B, et al. Mentors and role
models for women in academic medicine. West $f$ Med models for wom

1991;154:423-6.
9 Kram KE. Mentoring at work: developmental relationships in organisational life. Glenview, IL: Scott Fresman, 1985

10 Morzinski JA, Simpson DE, Bower DJ, et al. Faculty development through formal mentoring. Acad Med 1994;69: 267-9.

11 Wright $M$. An innovation in a diploma programme: the future potential of mentorship. Nurse Education Today 1990;10:355-9.

12 Spouse J. The effective mentor: a role model for student centred learning. Nursing Times 1996;92:32-5.

13 Raggins BR, Cotton JL. Mentor functions and outcomes: a comparison of men and women in formal and informal comparison of men and women in formal and informa
mentoring relationships. f Appl Psychol 1999;84:529-50.

mentoring relationships. F Appl Psychol 1999;84:529-50.
14 Douglas CA. Formal mentoring programs in organisations: an annotated bibliography. Greensboro, NC: Centre for Creative Leadership, 1997. 
15 Gaskill LR. A conceptual framework for the development, implementation and evaluation of formal mentoring programs. Fournal of Career Development 1993;20:147-60.
Murray M. Beyond the myths and magic of mentoring: how to facilitate an effective mentoring program. San Francisco: Jossey-Bass, 1991.
17 Zey MG. Mentor programs: making the right moves. Personnel fournal 1985;64:53-7.

8 Cupples SA. Selection, care and feeding of a research mentor. Alzheimer Dis Assoc Disord 1999;13 (suppl 1):S22-8.

19 Andrews M, Wallis M. Mentorship in nursing: a literature review. F Adv Nurs 1999;29:201-7.

\section{1st Asia Pacific Forum on Quality Improvement in Health Care}

\section{Three day conference}

\section{Wednesday 19 to Friday 21 September 2001 \\ Sydney, Australia}

We are delighted to announce this forthcoming conference in Sydney. Authors are invited to submit papers (call for papers closes on Friday 6 April), and delegate enquiries are welcome.

The themes of the Forum are:

- Improving patient safety

- Leadership for improvement

- Consumers driving change

- Building capacity for change: measurement, education and human resources

- The context: incentives and barriers for change

- Improving health systems

- The evidence and scientific basis for quality improvement.

Presented to you by the BMJ Publishing Group (London, UK) and Institute for Healthcare Improvement (Boston, USA), with the support of the the Commonwealth Department of Health and Aged Care (Australia), Safety and Quality Council (Australia), NSW Health (Australia), and Ministry of Health (New Zealand).

For more information contact: quality@bma.org.uk or fax +44(0)20 73836869 